\title{
O PROCESSO DE APRENDIZAGEM NA EDUCAÇÃO DE JOVENS E ADULTOS (EJA): AS VOZES DOS CIDADÃOS DA RESISTÊNCIA
}

\author{
Andrea Barros Daltro de Castro Costa (UNEB)* \\ Ana Paula Silva da Conceição (UNEB)**
}

\section{RESUMO}

Nesta pesquisa problematizamos sobre quais elementos interferem na aprendizagem dos estudantes do Tempo de Aprendizagem I (TAP I) nas escolas públicas de Salvador? O objetivo geral foi de identificar os elementos que contribuem e interferem na aprendizagem dos estudantes da EJA do TAP I nas escolas públicas de Salvador. Assim sendo, tivemos como objetivos específicos: investigar os processos de aprendizagem dos estudantes da EJA; relacionar o papel da escola cidadã com o processo de reconhecimento dos sujeitos da EJA. Optamos pela abordagem qualitativa, através do estudo de caso múltiplo com utilização da entrevista semiestruturada como técnica de pesquisa. Os resultados revelaram que a aprendizagem, para os estudantes da EJA, se dá através do processo de aquisição da leitura e da escrita; a maioria destes tiveram direitos negados de acesso à escola devido inserção precoce no trabalho; e a escola é espaço de construção, reconhecimento e ascensão social. Concluímos que a escola cidadã possibilita aos estudantes superação das trajetórias de vida, protagonismo no contexto social letrado e resistência à exclusão social.

Palavras chaves: Aprendizagem. Estudantes da EJA. Escola Cidadã. Resistência.

\section{ABSTRACT \\ THE LEARNING PROCESS AT EJA: THE VOICES OF CITIZENS OF RESISTANCE \\ In this qualitative investigation of the procedure multiple case study apply- ing the semistructured interview as instrument, we questioned which ele- ments interfere in the learning of the students of the Learning Time I (TAP I)}

* Professora Concursada da Rede Municipal de Ensino de Salvador. Mestranda do Programa de Educação de Jovens e Adultos - UNEB. Membro do grupo de pesquisa Formacceinfancia Linguagens e EJA - UNEB. E-mail: andrea.barros75@gmail.com ORCID: https://orcid.org/0000-0002-3928-4691

** Professora Adjunta da Universidade do Estado da Bahia (UNEB). Doutora em Educação pela Universidade Federal da Bahia. E-mail: apsconceicao@uneb.br ORCID: https://orcid.org/0000-0002-6958-7749 
in the public schools of Salvador? The main goal is to identify the elements that contribute and interfere in the learning of students of the TAP I EJA in public schools in Salvador, highlighting as specific objectives: To investigate the learning processes of EJA students; to relate the role of the citizen school to the process of recognition of the EJA subjects. The results show that learning for EJA students occurs through the process of acquisition of reading and writing; most of them had denied access to school due to their early insertion at work life; and the school is a space of construction, recognition and social ascension. We conclude that the citizens' school enables students to overcome their life trajectories, also protagonism in the social context and the resistance to social exclusion as well.

Keywords: Learning. EJA students. Citizen school. Resistance.

\section{RESUMEN}

\section{EL PROCESO DE APRENDIZAJE EN LA EDUCACIÓN DE JÓVENES Y ADULTOS (EJA): LAS VOCES DE LOS CIUDADANOS DE RESISTENCIA}

¿En esta investigación que problematizar sobre que elementos interfieren con el aprendizaje de los estudiantes aprendizaje tiempo (TAP I) en las escuelas públicas de el Salvador? El objetivo general fue identificar los elementos que contribuyen y que interfieren con el aprendizaje de alumnos de EJA TAP en escuelas públicas de el Salvador. Por lo tanto, tuvo como objetivos específicos: investigar los procesos de aprendizaje de los estudiantes de la educación de adultos y jóvenes; se relacionan con el papel de la escuela del ciudadano con el proceso de reconocimiento del sujeto de la EJA. Optamos por el enfoque cualitativo, a través del estudio de caso múltiple con la técnica de entrevista semiestructurada. Los resultados revelaron aprendizaje para los estudiantes de la educación de adultos y jóvenes, a través de la adquisición de la lectura y la escritura; la mayoría de ellas había negado los derechos de acceso a la escuela debido a la temprana inserción en el trabajo; y la escuela es espacio, reconocimiento y ascensión social. Concluimos que la escuela del ciudadano permite a los estudiantes superar las trayectorias de vida, papel en el contexto social alfabetizado y resistencia a la exclusión social.

Palabras clave: aprendizaje. Alumnos de la EJA. Escuela del ciudadano. Resistencia.

\section{INTRODUÇÃO}

Neste artigo analisamos a temática processos de aprendizagem nas classes da Educação de Jovens e Adultos na qual efetivamos uma discussão a respeito de abordagens de aprendizagem dos estudantes da Educação de Jovens e Adultos (EJA), tendo como base a percepção desses sujeitos muitas vezes marginalizados e sem oportunidades. Consideramos a sala de aula como um espaço para esse processo de construção e produção de conhecimento e a escola, instituição viva capaz de 
ressignificar o contexto educativo para os jovens, adultos e idosos.

Dessa forma, observamos que se trata de uma temática que sustenta um amplo processo reflexivo sobre quem são os estudantes e as estudantes, regressos da EJA nos seus múltiplos aspectos e especificidades que retornam ao espaço escolar com tantas dúvidas e incertezas que permearam sua trajetória de estudo durante a infância ou juventude por diversos motivos, sejam sociais, econômicos, políticos ou culturais. Ao retornarem ao ambiente formal de aquisição e produção de conhecimento científico, esses sujeitos desejam fazer parte do mundo letrado, a partir do reconhecimento de suas capacidades e potencialidades assim como, o respeito às suas limitações e dificuldades.

Por essa razão, delimitamos nossa análise na tentativa de responder ao seguinte questionamento: quais elementos auxiliam e interferem na aprendizagem dos estudantes e das estudantes do TAP I (definição da Resolução CME № 041/2013) nas escolas públicas da cidade de Salvador? Trata-se de uma questão que necessita ser estudada para elucidar dúvidas e refletir acerca do processo de aprendizagem destes sujeitos que muitas vezes desenvolvem trabalhos manuais e não tem tempo para dedicarse aos estudos formais. Vale ressaltar que essa investigação não emana do aprendizado de jovens e adultos como meta principal de ensinar as letras para que esses assinem seu nome, mas também que perceba a alfabetização como uma alavanca para a formação de cidadãos conscientes e capazes de atuar na vida social, resistentes à exclusão das injustiças sociais geradas pela baixa escolaridade.

Pesquisas sobre a aprendizagem dos jovens e adultos, iniciadas a partir do estudo da Andragogia, defendem que os estudantes e as estudantes da EJA devem participar de forma mais ativa do seu processo de aprendizagem por conta da maturidade e ricas experiências que favorecem o desenvolvimento da sua consciência crítica. Essas características também motivaram o estudo do problema acima citado e influenciaram na escolha dos sujeitos da pesquisa.

Para efetivar a investigação dessa problemática elegemos como objetivo geral identificar os elementos que contribuem e interferem na aprendizagem dos estudantes e das estudantes da EJA do TAP I nas escolas públicas da cidade de Salvador. A partir das falas dos estudantes e das estudantes desse estágio, oportunizamos a esses sujeitos pensar sobre o seu processo de aprendizagem, a partir do seu contexto atual enquanto trabalhadores e trabalhadoras, ancorando suas expectativas na possibilidade de gerar uma reflexão sobre a prática dos profissionais que atuam nesse segmento.

Como objetivos específicos destacamos: - investigar os processos de aprendizagem dos estudantes e das estudantes da EJA; relacionar o papel da escola cidadã com o processo de reconhecimento dos estudantes e das estudantes da EJA. Essa escolha foi ressaltada pela necessidade de aprofundar a discussão a partir do protagonismo dos estudantes e das estudantes da EJA que durante muito tempo sentiram-se obrigados a abrir mão do seu direito de estudar, assim como da necessidade de configurar o papel da escola enquanto espaço de resistência e desenvolvimento da cidadania.

Essa investigação é bastante salutar por oportunizar reflexões sobre a urgência de conhecer melhor as demandas dos estudantes e das estudantes da EJA, sujeitos oprimidos e que ao retornar para a escola acreditam na educação cidadã e libertadora capaz 
de superar a desumanização. Nesse processo educativo, é imprescindível escrever, biografar-se, ler, historicizar-se, assumir-se, reconhecer-se como ser incompleto, capaz de gerar conhecimentos ao longo da vida, incitar o diálogo para reverberar a produção da cultura e da própria existência por romper o silêncio que é viés de opressão e, cultivar a fala crítica da voz analítica que favorece a tomada de consciência da própria vida, tornando-se um ser político.

Organizada por esta introdução, composta pela temática, o problema, os objetivos geral e específico, temos a parte inicial da investigação. Apresentamos também os procedimentos metodológicos embasados na abordagem de investigação qualitativa e a metodologia do trabalho, na perspectiva do estudo de casos múltiplos, destacando os sujeitos, o contexto dos locais de pesquisa, os instrumentos aplicados, as etapas percorridas pelo pesquisador e a análise das informações coletadas atreladas ao suporte teórico. 0 texto, permeado por diversas vozes dos estudantes e das estudantes, aborda na prática sobre o seu processo de aprendizagem favorecendo o repensar das práticas de professores e professoras a partir da construção do elo entre saberes e aprendências dialógicas.

\section{PROCEDIMENTOS METODOLÓGICOS}

A base metodológica da pesquisa quanto à abordagem, com inspiração em Triviños (2012) e Godoy (1996), foi a pesquisa qualitativa por focar aspectos da realidade não quantitativos e investigar fenômenos na sua profundidade. Esse modelo teórico-metodológico adotado, compreende a importância do estudo do fenômeno educacional como fenômeno social e ao investigar suas raízes, causas, consequências, percebe o sujeito como ser social e histórico. Baseado no enfoque crítico participativo com visão histórico-estrutural-dialética parte do princípio de "[...] conhecer a realidade e transformá-la em processos contextuais e dinâmicos complexos" (TRIVIÑOS, 2012, p.117).

Para elencar elementos dessa abordagem, salientamos as ideias de Godoy (1996, p. 62-63) quanto às características: é essencial o contato do pesquisador com o ambiente investigativo; o registro dos resultados prioriza muito a escrita, abolindo as expressões quantitativas de análise e reconhece o ambiente e as pessoas envolvidas no contexto holístico pois o pesquisador preocupa-se com o processo e não somente com os resultados; o pesquisador compreende o fenômeno a partir das perspectivas dos sujeitos envolvidos e "pesquisadores utilizam o enfoque indutivo na análise de seus dados" pois o aporte teórico é construído aos poucos e "à medida que coleta os dados e os examina".

Quanto ao procedimento estratégico, trata-se de um estudo de caso múltiplos baseado nas definições de André (2013), Alves-Mazzotti (2006) e Yin (2015) o qual favorece o diálogo com os envolvidos pelo estudo da temática, além de permitir a cumulatividade e aplicabilidade dos resultados encontrados a partir dos instrumentos, uma rápida observação direta e a entrevista semiestruturada contextualizada nas ideias de Ornelas (2011).

0 estudo de caso múltiplos fornece informações importantes e permite decisões políticas por contribuir para a reflexão significativa no âmbito educacional. A eficiência desse estudo transcorre do seu detalhamento e ênfase na atuação ética, crítica e criativa do pesquisador sem se deixar perder nas aparências, pois esse procedimento exige a manifestação de suas dimensões intelectual, 
pessoal e emocional o que gera a integração harmoniosa do pesquisador ao grupo.

$\mathrm{Na}$ área educacional, o estudo de caso aparece com o sentido limitado por volta das décadas 60 e 70 como estudo descritivo e considerado menos científico por não ser experimental. Nos anos 80 , ressurge na pesquisa com sentido mais abrangente, focalizar um fenômeno específico a partir do seu contexto e dimensões múltiplas, valorizando o aspecto unitário e ressaltando a análise situada e profunda. Nessa perspectiva, a autora Marli André (2013) reforça que não é o nome que estabelece o rigor metodológico, mas o detalhamento da descrição e a justificativa de cada opção feita, como a escolha adequada dos sujeitos, dos procedimentos de coleta e análise de informações, assim como a elaboração e validação dos instrumentos no tratamento das informações.

Dessa forma, o trabalho presente faz uma descrição detalhada das etapas de pesquisa, apresentando os locais do estudo (preservando o nome das instituições para resguardar a identidade dos estudantes entrevistados), a motivação da escolha dos sujeitos e sua caracterização, os instrumentos de coletas de informações e a fundamentação dessas informações para embasar com cientificidade os resultados encontrados de forma construir uma teia entre as falas dos entrevistados e as teorias.

Conforme classificação de Yin (2015, p.84), esse estudo de caso múltiplo é integrado "[...] porque os resultados de cada levantamento não serão agrupados entre as escolas. Ao contrário, os dados do levantamento serão parte dos achados para cada escola ou caso individual". De acordo com André (2005), esse estudo de caso realiza-se em três fases: a fase exploratória momento em que o pesquisador entra em contato com as escolas através de seus re- presentantes da gestão e informa o objetivo da pesquisa, agendando os dias de visita e entrevista. Por conta do tempo disponibilizado pelo pesquisador, a apresentação do contexto da pesquisa aconteceu no mesmo dia das entrevistas com os estudantes e estudantes, assim como o reconhecimento do ambiente escolar, concomitante com uma breve observação a fim de perceber a relação dos sujeitos envolvidos nas instituições.

A segunda fase, a de coleta dos dados foi realizada através da entrevista semiestruturada com todos os estudantes e as estudantes do TAP I presentes nas escolas no dia previsto com a gestão a fim de garantir uma maior confiabilidade nos resultados, o que nos garantiu a possibilidade de conhecer a partir das expressões dos estudantes o que interfere ou auxilia nos seus processos de aprendizagem.

Vale ressaltar que foi necessária uma apresentação coletiva na sala de aula com a professora regente presente, expondo a investigação que pretendíamos realizar visto que inicialmente alguns estudantes se recusaram a participar da entrevista.

0 exercício da entrevista exige leveza, é um exercício meticuloso, requer um tempo necessário para que a confiança se presendifique, sabe-se o quanto a fala está ancorada na censura, no medo, nas reticências, em lapso, atos falhos, silêncios. [...] para que o conteúdo revelado tenha saber e sabor de uma imagem que, [...] encontre o significado e o significante do objeto perdido. (ORNELAS, 2011, p. 29)

$\mathrm{Na}$ apresentação foi fundamental expor o interesse pela pesquisa através do relato do objetivo geral assim como a escolha deles enquanto sujeitos desse estudo, considerando-os os envolvidos diretos e por isso os únicos capazes de revelar com muita fidedignidade os pontos levantados. Também a apresentação da pesquisadora 
como professora desse tempo de aprendizagem que respeita a história e momento de cada um, pois conhece a realidade dos estudantes trabalhadores e trabalhadoras, no espaço educativo, tendo uma trajetória construída de aprendizagem com esses sujeitos há treze anos.

A entrevista é um momento de questionar o entrevistado que muitas vezes tem medo ou fica em dúvida de não saber o que responder, cabendo ao entrevistador através de uma conversa informal encontrar a hora exata de iniciar a entrevista que exige experiência, boa comunicação e a sensibilidade e pureza da escuta. Momento bastante rico e significativo porque muitos perceberam que a pesquisa não tinha a intenção de avalia-los ou fazer exposição das suas experiências ou dificuldades, mas era uma possibilidade de externar suas expectativas para que o processo de aprendizagem fosse também o retrato de seus anseios e colocações.

Por isso, destacamos o quão é importante o vínculo do pesquisador com a realidade estudada assim como o conhecimento prévio dos sujeitos envolvidos, a fim de construir uma confiança que favorece a essência real das falas, compreendendo a potência da palavra. Como defende Ornelas (2011, p. 74) é preciso “[...] enxergar os sujeitos da pesquisa, não mais iguais, mas deixar emergir a singularidade e, nesse instante, o pesquisador e os seus sujeitos operam com o desejo de saber".

É importante elucidar que nessa etapa afloraram sentimentos de pertencimento à modalidade da EJA e a importância do olhar significativo para suas especificidades, reconhecendo-a como espaço de resistências, lutas e superações tanto no aspecto físico (o cansaço do cotidiano) quanto no emocional (a vergonha de se achar além da idade para estar na escola e não dominar o letramen- to). Essas características estiveram presentes constantemente nas entrevistas, espaço dinâmico, porque a todo instante os entrevistados recorriam as suas histórias de vida gerando momentos de prazer e dor exigindo do entrevistador muito cuidado para não se desviar do roteiro inicial, visto que esse instrumento se configura numa via de mão dupla onde ambos têm liberdade para falar fora do previsto. Esse exercício de escuta, espaço de ética, atenção e cuidado possibilitou a sustentação ao objeto de estudo da investigação no qual pretendemos teorizar, pois permitiu a compreensão detalhada e minuciosa dos valores e crenças dos sujeitos entrevistados.

A entrevista semiestruturada, gravada, com autorização dos entrevistados, e escutada no final, de forma a descortinar cada fala, possibilitou ao entrevistador descobrir todo o brilho, força e sentimentos que permeavam cada resposta. Às vezes gerava mal-estar, por trazer lembranças difíceis, mas sempre encorajadas porque revelava muitos sujeitos de falas, mas também de faltas, o que exigiu de o entrevistador perceber as nuances dos silêncios, muitas vezes com as lágrimas contidas na garganta do entrevistado.

[...] A gravação permite contar com todo o material fornecido pelo informante, o que não ocorre seguindo outro meio. Por outro lado, e isto tem dado para nós muitos bons resultados, o mesmo informante pode ajudar a completar, aperfeiçoar e destacar etc. as ideias por ele expostas, caso o fizermos escutar suas próprias palavras gravadas. (TRIVIÑOS, 2012, p. 148)

Foram quatro questões-guia denominadas assim por servirem de norte para conduzir de forma objetiva o diálogo oportunizado pela entrevista: 1 - 0 que foi mais difícil para você voltar a estudar?; 2- Quais as aulas 
que você mais gosta e que faz você aprender mais?; 3 - 0 que te ajuda e atrapalha na hora de aprender? 4- 0 que é a escola para você? Esse processo metodológico suscita informações valiosas, pois fecunda decisões políticas enquanto ações desenvolvidas no contexto sala de aula que interferem de forma positiva ou não o processo de aprendizagem dos estudantes da EJA, visto que ensinar é também um ato político.

Por fim, a fase de análise sistemática dos dados, que em alguns momentos esteve conjugada com a coleta de dados, traçadas como linhas gerais para condução desse tipo de investigação. Foram registradas as falas dos estudantes e das estudantes na íntegra, fazendo a transcrição de forma a exemplificar com muita vivacidade as questões teóricas encontradas nas referências escolhidas. Esses registros, em consonância com o suporte científico, envolvem os leitores e leitoras a respeito de histórias de vida recheadas de sentimentos que nos ensina e nos faz aprender através da possibilidade dialética de construir-se no processo de construção do outro.

As escolas públicas, lócus da pesquisa, ficam situadas em bairros distintos: Vitória, Pelourinho e Brotas, porém próximos do centro da cidade por apresentarem melhor acesso. Foram três escolas com contextos variados e descritos abaixo que possibilitou generalizar os resultados da pesquisa. A escola 1 será representada como E1 fica localizada no bairro da Vitória, a escola 2 denominada E2 situada no Pelourinho e outra em Brotas considerada como E3.

A E1 é conveniada, funciona nos três turnos (matutino com o Fundamental I, vespertino pré-escola e o Fundamental I e o noturno com EJA do 1 o Segmento), tem 64 estudantes do total matriculados na EJA e iniciou o funcionamento dessa modali- dade em 2003 quando foi municipalizada. Apresenta o IDEB superior à meta estabelecida no ano de 2017, tendo média de 6,3 enquanto a meta municipal era de 5,4 e participa no contexto nacional do percentual de $18,45 \%$ das escolas com desempenho acima da nota.

É considerada uma escola de pequeno porte, tendo no total: cinco salas amplas, sala de direção e secretaria, sala de professores e coordenação, área de parque descoberto, sala de leitura, acesso à internet e refeitório. No quadro da gestão, uma diretora, uma vice para cada turno do diurno e três coordenadoras (uma para o matutino, uma para o vespertino e uma para o noturno).

A E2 é enquadrada no Grupo 03 do Indicador de Nível Socioeconômico (INSE) com localização diferenciada como unidade de uso sustentável, tem 70 estudantes no total matriculados na modalidade EJA do $1^{\circ}$ e $2^{\circ}$ Segmento, tendo 39 no $1^{\circ}$ Segmento, sendo mista as turmas dos matriculados nos TAP I e TAP II. Seu IDEB revela crescimento nos últimos dois anos, mas apresenta média de 3,9 abaixo da meta municipal de 4,6 e participa no contexto nacional do percentual de $12,49 \%$ das escolas com desempenho abaixo da nota.

Considerada uma escola de porte médio possui uma diretora e duas vices, uma coordenadora para cada turno no diurno e duas coordenadoras no noturno (uma para o $1^{0}$ Segmento e outra para o $2^{\text {o Segmento) } 0}$ diurno atende às séries da Educação Infantil e Fundamental I e o noturno a EJA. Funciona com a modalidade EJA desde 2017 quando iniciou o Programa Telecurso. No total são sete salas pequenas, climatizadas com ar condicionado, sala de direção, refeitório e acesso à internet.

Com 139 estudantes do total matriculados na modalidade EJA sendo 75 do $1^{\text {o }}$ 
Segmento, E3 apresenta o IDEB superior à meta estabelecida no ano de 2017, tendo média de 4,6 enquanto a meta municipal era de 4,3 , participa no contexto nacional do percentual de 25,89\% das escolas com desempenho acima da nota. No total são seis salas amplas (mas para EJA funcionam apenas cinco) e mais uma sala de direção e secretaria, sala de professores e coordenação, quadra de esporte e acesso à internet e refeitório.

Escola de porte grande tem uma equipe gestora formada por uma diretora, três vices (uma para cada turno) e uma coordenadora para cada segmento. Funciona nos três turnos, sendo o diurno voltado para o Ensino Fundamental II e o noturno para a EJA no $1^{\circ}$ e $2^{\circ}$ Segmento. A EJA funciona desde quando a escola foi municipalizada, em 2013.

Participaram da entrevista 22 estudantes das três escolas acima detalhadas os quais terão suas identidades preservadas. Dessa forma serão utilizados nomes fictícios nos momentos dos registros de suas falas, transcritas na íntegra para retratar a veracidade do que foi gravado assim como transmitir através dos registros a intensidade das expressões desses sujeitos. Na sua maioria mulheres, 14 dos entrevistados totalizando $64 \%$, trabalham fora, assumem os afazeres domésticos e estudam, e apenas 8 homens totalizando 36\% que também são trabalhadores e estudam. A faixa etária desses sujeitos está entre 30 e 70 anos sendo $23 \%$ no intervalo de 30 a 40 anos, $23 \%$ entre 40 e 50 anos, 36\% entre 50 e 60 anos, 14\% acima de 60 tendo $4 \%$ dos entrevistados que não revelaram sua idade.

Essas porcentagens revela uma educação de possibilidades configurando a alfabetização de adultos como estratégia de superação e reversão da perversidade epistemológica do capitalismo que atrela saber e poder ao domínio de capital. Os estudantes e as estudantes são trabalhadores e trabalhadoras que em sua maioria exercem funções assalariadas, reverberando o discurso marxista da exploração da força de trabalho pelo sistema capitalista o que gera a exclusão da classe trabalhadora. 38\% são empregados domésticos, 33\% autônomos (ambulantes, pequenos empreendedores), 9\% aposentados, $5 \%$ garçom, $5 \%$ cabelereiro, $5 \%$ donas de casa e os outros 5\% desempregados.

Essas características específicas, que configuram o contexto da EJA, assim como a certeza da importância de dar vez e espaço, para as vozes dos sujeitos, seres incompletos e inacabados, que vivenciam a/na EJA, a sua capacidade de superação e confiança na aprendizagem como construção de cidadãos e cidadãs tendo então o reconhecimento dos seus direitos, foram os motivos justificáveis pela opção de os entrevistados serem os estudantes e as estudantes.

\section{A APRENDIZAGEM E A ESCOLA CIDADÃ: DESAFIOS E RESISTÊNCIA DA EJA}

A preocupação com o processo de aprendizagem dos adultos como uma construção diferente do das crianças surgiu com os estudos da Andragogia, compreendida como a arte e ciência de facilitar a aprendizagem dos adultos. Essas contribuições possibilitaram a compreensão de que os processos de aprendizagem não estão reservados a um tempo certo e/ou determinado, o que expandiu consideravelmente as oportunidades e a promessa da educação ao longo da vida.

Entretanto, esse estudo recebeu críticas e DeAquino (2007) se reporta a Sandra Kerka, pesquisadora da área de aprendizagem, para relatar a dissociação entre o que diz a andragogia a respeito da aprendizagem dos adultos e a realidade. 
...] não é correto presumir que todos os adultos terão um melhor desempenho em termos de aprendizagem em um ambiente centrado no aprendiz, porque muitos deles não estarão dispostos nem serão capazes de assumir pelo menos parte da responsabilidade pelo aprendizado [...]. Outro ponto levantado nesse trabalho é a desmistificação de que os alunos acumulam uma miríade de ricas experiências ao longo de sua vida e acabam utilizando-a como recurso para a aprendizagem. Muitos adultos não realizaram muito em sua vida [...]. Um terceiro mito derrubado é que todos os adultos têm uma motivação interna, intrínseca, para aprender. Alguns deles precisam de motivadores externos, como notas e competições [...] (DEAQUINO, 2007, p.14)

Outra característica que deve ser considerada é que a Andragogia não diferencia os adultos aos quais se referem. Geralmente trata-se dos adultos que buscam ampliação de conhecimentos, já passaram por outros processos de formação, mas não foram excluídos dos direitos à escolarização e por isso não pode ser efetivada na sua íntegra aos sujeitos da EJA, visto que o contexto dos adultos é bastante divergente, com diferentes singularidades e carregados de todas as especificidades que por si só já define essa modalidade de ensino como reparadora à negação de direitos.

Ainda são poucos os suportes teóricos sobre os processos de aprendizagem dos estudantes da EJA, o que caracteriza um déficit exploratório no que tange o desenvolvimento cognitivo. Dessa forma, essa pesquisa empírica serve de embasamento para algumas definições em relação aos aspectos que auxiliam e que atrapalham a construção dos conhecimentos dos adultos ao retornarem para as instituições formais de ensino.

No âmbito da psicologia do desenvolvimento, os estudos, em sua maioria, são voltados para as crianças e não para os adultos, o que torna o processo da aprendizagem dos estudantes e das estudantes da EJA um objeto de pesquisa pouco explorado. Jesus Palácio (2004) ressalta que o desenvolvimento a partir da adolescência está relacionado à idade psicológica e social, fase aberta a mudanças e influenciada por diversos fatores: o nível de saúde, a experiência do trabalho, sua motivação, os grupos que convivem e as situações diárias que superam.

Vygotsky (1996) defende que o percurso de desenvolvimento, definido de certa forma pela maturação dos indivíduos, está interligado ao convívio com um ambiente cultural e que o aprendizado potencializa o desenvolvimento dos processos internos. Assim, destaca que o indivíduo só aprende a leitura e a escrita se conviver no ambiente que desperte os processos internos para a aquisição dessas habilidades. Por isso acrescenta que o sistema escolar desempenha um papel importante em estruturar situações propícias ao aprendizado, uma vez que a linguagem deve ser, em parte, ensinada, para ser aprendida.

Nesse sentido, esse autor destaca o termo desenvolvimento da zona proximal, caminho que o indivíduo percorrerá para desenvolver funções ainda não amadurecidas e que serão consolidadas a partir da ajuda de outro e por isso está sempre em transformação. A interação social assume caráter essencial no processo de construção das funções psicológicas humanas, pois não existe processo de desenvolvimento se não existir a interação entre indivíduos da mesma espécie, assim como, não existe desenvolvimento cognitivo se não almejar metas alcançáveis a partir o conhecimento inicialmente já consolidado. 
Respeitar a leitura de mundo do educando significa torná-la como ponto de partida para a compreensão do papel da curiosidade, de modo geral, e da humana, de modo especial, como um dos impulsos fundantes da produção de conhecimento. No fundo, o educador que respeita leitura de mundo, reconhece a historicidade do saber, o caráter histórico da curiosidade. (FREIRE, 2011b, p. 120)

Vale ressaltar que a mediação não pode ocorrer numa ação pedagógica diretiva, sendo o estudante um mero receptor. É indispensável acreditar na ideia de reconstrução e transformação dos significados desenvolvidos a partir da vivência com os grupos culturais. E essa reconstrução cultural é a base da construção do processo histórico de cada sujeito. Segundo a teoria de Vygotsky a inserção de indivíduo no ambiente cultural é premissa para a sua própria constituição enquanto pessoa e essa interação é o que possibilita o desenvolvimento das atividades psicológicas que envolve o aprendizado.

De acordo com a psicologia evolutiva, a história de vida e o processo de formação estabelecido com e nas relações de convivência possibilita que cada adulto traga consigo diferentes habilidades e dificuldades, ocasionando maior reflexão sobre seu processo de aprendizagem. Essa compreensão nos remete à ideia de que a educação de jovens e adultos está intrinsecamente relacionada com a especificidade cultural.

Oliveira (2007) destaca a linguagem escolar como um dos obstáculos para a aprendizagem dos adultos sobrepondo-a ao conteúdo. As referências de escola que se traz ao longo da vida é sempre a ideia de um professor que determina as ordens, cadeiras uma atrás da outra, um quadro negro, todos trabalhando com lápis e caderno e comandos apresentados na sua maioria através da forma escrita, o que constitui grande parte do problema para ser resolvido. Apesar da aprendizagem está relacionada com questões cognitivas, aspectos afetivos também geram desconforto nos adultos, provocando então a exclusão da escola.

Dessa forma, os estudos relacionados ao processo de aprendizagem dos adultos se dedicam à compreensão "[...] da homogeneidade e da heterogeneidade cultural, do confronto entre diferentes culturas, diferenças culturais e diferenças nas capacidades e no desempenho intelectual dos sujeitos" (OLIVEIRA, 2007, p. 66)

Com base nesses aspectos podemos citar três abordagens distintas ao perceber as relações entre cultura e o funcionamento intelectual. A primeira, bastante determinista, defende os fatores culturais como determinantes dos traços do psiquismo, ou seja, as pessoas que vivem em grupos menos escolarizados são consideradas menos desenvolvidas e incapazes de desenvolverem o pensamento abstrato. A segunda, considerada como relativismo radical, valoriza igualmente todo conhecimento restando pouco espaço para a intervenção educativa, visto que o desenvolvimento psicológico e os conhecimentos prévios dos adultos necessitam ser respeitados. A cultura e a história, elementos mobilizadores do desenvolvimento dos processos cognitivos, independente do seu grupo cultural e social, tornam-se elementos secundários. A terceira, mais promissora para o entendimento das relações entre cultura e modalidade de ensino, defende o processo de construção interno e externo ao longo da história dos adultos, diferentes ou não na sua origem, como motivador para o desenvolvimento cognitivo.

Corroboram com essa abordagem autores que defendem a complexidade do letramento (estado ou condição de quem se 
envolve nas diversas práticas sociais de leitura e de escrita) como fenômeno cultural. Vera Ribeiro (1998) enfatiza que a aprendizagem da leitura e da escrita produz mudanças psicológicas e por isso as variedades das práticas de alfabetismo atreladas às peculiaridades culturais dos grupos devem ser compreendidas e valorizadas. Cláudia Vóvio (2013) destaca que independente da escolaridade dos sujeitos, a participação em situações comunicativas favorece a articulação entre o desenvolvimento de habilidades cognitivas e os conhecimentos linguísticos ao falarmos ou escrevermos.

As vantagens trazidas pela aprendizagem da leitura e da escrita é perceptível em todos os momentos nos quais escutamos os estudantes e as estudantes. 0 desejo aparentemente tão óbvio não é, porque esses sujeitos já passaram por diversas situações constrangedoras que os fizeram sentir-se menosprezados e inferiorizados. A riqueza cultural, os conhecimentos prévios dessas pessoas os tornam produtores de saber, capazes de aprender e essa conquista transforma-se em mola impulsionadora para o desejo de novas descobertas.

Soares (2012) destaca a importância da aprendizagem da leitura e da escrita, afirmando que todo indivíduo que faz uso dessas habilidades transforma-se sob os aspectos sociais, culturais e cognitivos. Nesse contexto, diferencia os termos alfabetização e letramento, partindo do pressuposto que analfabeto é aquele que não consegue exercer, na sua plenitude, os seus direitos enquanto cidadão, sujeitos, na sua maioria, marginalizados pela sociedade por não terem acesso a bens culturais da sociedade letrada.

Um adulto pode ser analfabeto porque marginalizado social e economicamente, mas se vive em um meio em que a leitura e a escrita tem presença forte, se se interessa em ouvir a leitura de jornais feita por um alfabetizado, se recebe cartas que outros leem para ele, se dita cartas para que um alfabetizado as escreva [...] esse analfabeto é de certa forma letrado, porque faz uso da escrita, envolvese em práticas sociais de leitura e de escrita (SOARES, 2012, p.24)

Assim, o letramento é perceber a função social da escrita nas diversas situações cotidianas e descobrir-se pela leitura e pela escrita e também descobrir o mundo a sua volta. É perceber o que se pode ler, interagir com diferentes portadores textuais, suas funções e envolver-se nas mais variadas práticas sociais da leitura e da escrita, de forma a conseguir resolver questões diárias com autonomia.

Entretanto, o desconhecido gera medo e os estudantes e as estudantes da EJA mesmo percebendo a grandeza da prática da leitura e da escrita por estarem diretamente relacionadas com situações da vida prática (pagar uma conta, ler a bíblia, ir ao supermercado) sentem-se inseguros. Quando conseguem superar o medo e a resistência ao saber descobrem a força da autonomia e a preciosidade da independência tanto subjetiva, por começar a perceber-se como sujeito reconhecido socialmente, como objetiva, desejando superar o desemprego, salários melhores, ser exemplo para os filhos ou filhas, netos ou netas, visualizando-se então como seres políticos capazes de construir sua própria história.

Pensar no fazer pedagógico com essa nuance e enquanto ação coletiva é refletir sobre o papel da escola na formação dos educando e educandas assim como na construção coletiva dos saberes significativos de forma a valorizar os sujeitos enquanto cidadãos históricos e políticos que através do diálogo buscam encontrar possibilidades marcadas pelo amor, poder e 
saber. A tarefa do educador é dar sentido às informações, é técnica, mas também é arte, uma ciência do conhecer e ler a realidade para transformá-la.

Nesse contexto, a escola torna-se um lugar de educar para fora, fazer avançar. É um espaço onde se constrói e se pensa o futuro de cada pessoa, onde a participação e autonomia compõem a natureza do ato pedagógico e pressuposto da própria aprendizagem. Como destaca Gadotti formar para a participação é também formar para a cidadania onde os cidadãos envolvidos nessa ação educativa participam com responsabilidade e ética do destino do país, contextualizando então uma filosofia educacional ancorada numa concepção emancipatória e democrática.

A escola necessita ser desafiadora, onde elaborar perguntas é a oportunidade de elaborar saberes, porque saber perguntar é trilhar caminhos de desafios. Essas indagações impulsionam um novo olhar para os estudantes que adentram essa instituição de saber, sujeitos envolvidos no mundo globalizado, mas também repleto de exclusões sociais e negações de direitos às populações menos favorecidas, retrato dos regressos da EJA. A busca por uma melhor condição de vida torna a escola um local de produção cultural, rico e recheado de heterogêneas histórias de vida, obrigando um olhar minucioso para a realidade dos sujeitos que retornam ao ambiente do saber.

Mostrar os diferentes caminhos do conhecimento, da participação e da formação integral do aluno, é o dever da escola moderna e dos seus professores. Nesse sentido, ao receber os seus estudantes, o professor e a escola devem iniciar um processo de estudo da realidade, demonstrar que ela não é estática, desprovida de ações criativas; ao contrário, é preciso demonstrar que há no meio popular muito dinamismo que se reveste de ca- racterísticas culturais próprias. (AMORIM, 2007, p. 99)

A busca por uma escola de qualidade na EJA é uma luta de todos os envolvidos da ação pedagógica, a realidade do analfabetismo no Brasil, principalmente nas regiões mais empobrecidos, é gritante e urge ações coesas e frutíferas. A escola como via de desenvolvimento das habilidades de leitura e escrita, onde os sujeitos se sentem acolhidos, se escutam e se constroem com as trocas, torna-se o chão da materialidade das histórias de vida.

Conforme termo criado por Paulo Freire, a escola necessita ser cidadã, a que reconhece os sujeitos como seres inacabados na sua completude, respeita as características histórico-sociais da realidade local, sem perder de vista a produção do conhecimento crítico e científico. Para tanto é indiscutível a elaboração de um projeto político e pedagógico com bases filosóficas dialéticas, percebendo a ação educativa como ato de amor, beleza e pureza, portanto ação que envolve técnica, criatividade e sensibilidade. Por isso a escola cidadã é viva, flexível que se constrói saberes com sentimentos, onde todos se constroem, se assumem, onde os direitos são reconhecidos e nunca negados.

\section{RESULTADOS: A}

\section{APRENDIZAGEM NO ESPAÇO DE CONSTRUÇÃO DA CIDADANIA}

A pesquisa destinada â Educação de Jovens e Adultos ainda é considerada uma investigação nova, o que possibilita uma gama de elementos e fenômenos para esse estudo. Por adentrar nesse campo de investigação de forma a compreender as especificidades do processo de aprendizagem dos estudantes dessa modalidade, os sujeitos dessa pesquisa foram os estudantes do TAP I de 
escolas públicas do centro de Salvador, regressos, que se ausentaram da escola por diversos motivos e que retornam nesse ano letivo de 2018.

Esses elementos nos remetem às considerações que os sujeitos da EJA são adultos que lutam para superar suas condições precárias de vida (moradia, saúde, alimentação, transporte, empregos, etc) e trajetórias perversas de exclusão que se enraízam no analfabetismo, o que torna urgente uma educação reparadora de direitos. Essa realidade é claramente retratada pela estudante Maria quando se emociona ao falar:

A dificuldade da vida me faz eu querer aprender mais porque hoje em dia eu trabalho de diarista, não é menosprezando as pessoas que eu trabalhe, mas hoje em dia é um trabalho pouco reconhecido, então eu acho que uma pessoa que trabalha com uma pessoa, eu tenho o sonho de fazer alguma coisa ainda, ser alguém na vida e trabalhar futuramente naquilo que eu quiser porque em cada casa da família que eu trabalho, não é falando mal não das pessoas que eu trabalho, mas também é um trabalho que não é valorizado, cada dia está pior, hoje em dia só falta voltar a botar a gente para o tronco, só está faltando a escravidão voltar porque, com as leis aí tirando os direitos das empregadas domésticas, as pessoas estão se aproveitando, colocando as pessoas para trabalhar demais e ganhar pouco, Por isso eu acho que eu acredito em mim e cada dia eu vou passando uma experiência para mim mesma, no meu trabalho, aí eu vou vendo e digo para mim mesmo eu vou conseguir, eu vou chegar lá eu vou sair dessa. (Maria, 53 anos)

Com base nos dados do gráfico abaixo, vale destacar os diversos motivos pelos quais os estudantes e as estudantes se ausentaram ou nunca participaram da escolarização a fim de conhecer mais uma dentre tantas outras especificidades dessa modalidade de ensino.

Gráfico 01: Motivos que fizeram os estudantes e as estudantes ficarem tanto tempo longe da escola

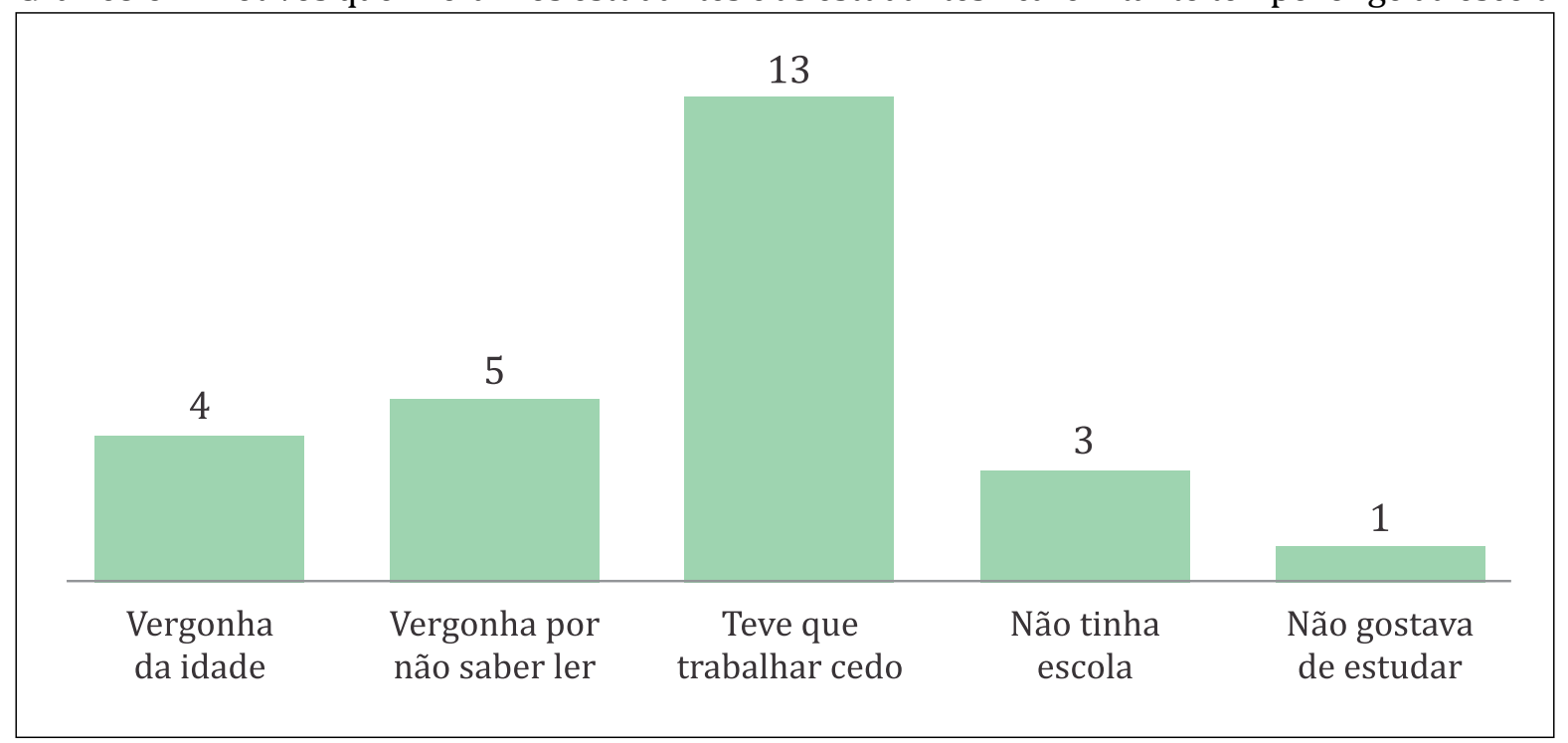

Fonte: Elaborado pelos autores, 2018.

Destacado por 13 entre os 22 entrevistados, o trabalho configurou-se como o motivo que mais interfere para o afastamento da escola por parte dos estudantes e das estudantes da EJA, revelando como citado anteriormente que a não permanência na escola por esses sujeitos configura-se como uma realidade socioeconômica excludente que envolve camadas da população mais pobres e por isso necessitam abandonar 
a escola ou nunca frequenta-la. Da mesma forma, 09 sujeitos destacaram a questão da vergonha, tanto de não saber ler e escrever, quanto da idade por se considerarem muito velho para retornar à escola; 03 relatam a inexistência de escolas onde moravam e apenas um estudante relatou que não gostava de estudar.

Conforme descrito no Parecer CNE/CEB 11/2000,

Se as múltiplas modalidades de trabalho informal, o subemprego, o desemprego estrutural, as mudanças no processo de produção e o aumento do setor de serviços geram uma grande instabilidade e insegurança para todos os que estão na vida ativa e quanto mais para os que se vêem desprovidos de bens tão básicos como a escrita e a leitura. 0 acesso ao conhecimento sempre teve um papel significativo na estratificação social, ainda mais hoje quando novas exigências intelectuais, básicas e aplicadas, vão se tornando exigências até mesmo para a vida cotidiana. (CNE/CEB 11/2000, p. 9)

A partir desses dados percebemos essa característica dos estudantes e das estudantes como uma das especificidades que configuram a EJA e necessita ser levada em conta no que diz respeito ao processo de aprendizagem e à atuação dos professores. A dupla jornada diária do trabalho e do estudo gera cansaço, o que muitas vezes afastam esses estudantes e essas estudantes da escola, fazendo com que alguns e algumas se matriculem e abandonem várias vezes sem completar os estudos que tanto almejam. Outro elemento importante é que, por conta das dificuldades de leitura e escrita que a maioria dos estudantes e das estudantes apresentam, muitas vezes, alguns professores infantilizam as atividades na tentativa de superar essas dificuldades e desconsideram a diversidade e riqueza dos conhecimentos que os estudantes e as es- tudantes trazem das suas experiências de vida.

Esses dados apresentam a caracterização dos sujeitos da EJA trazida por Faria, revelando que

São, ainda, indivíduos que carregam consigo duas marcas principais, uma, a de que nunca frequentaram a escola e a outra que já tiveram acesso à educação formal, mas que, por conta do trabalho e da luta pela própria sobrevivência, não deram continuidade ao processo de escolarização (FARIA, 2012, p.7).

A EJA é planejada como educação voltada para pobres, para jovens e adultos pertencentes às camadas populares, excluídos do sistema educacional e que almejam uma condição mínima de escolaridade que se configura na aquisição da leitura e da escrita, a alfabetização. Para Camargo e Furlanetti (2010, p. 9) “[...] a Educação de Jovens e Adultos constitui-se como produto da miséria social, das precárias condições de vida da maioria da população e dos males do sistema público regular de ensino (o não aproveitamento de escolaridade na época apropriada)".

Vale observar que os valores são superiores ao total de entrevistados, pois os estudantes tiveram liberdade de indicar mais de um motivo (a partir de sua história em relação a falta de oportunidade de estudo quando mais novos) dentre os quais os afastaram da instituição escolar. É evidente a variável "trabalho" no período da infância, como elemento excludente da presença de alguns sujeitos na escola, configurando que a maioria dos matriculados no Tempo de Aprendizagem (TAP I) são pessoas que tiveram que optar pela sobrevivência ou pela escola.

Outra característica importante para ser analisada é o tempo de permanência de cada estudante, como pode ser visto a seguir. 
Gráfico 02: Permanência na escola dos estudantes e as estudantes do TAP I

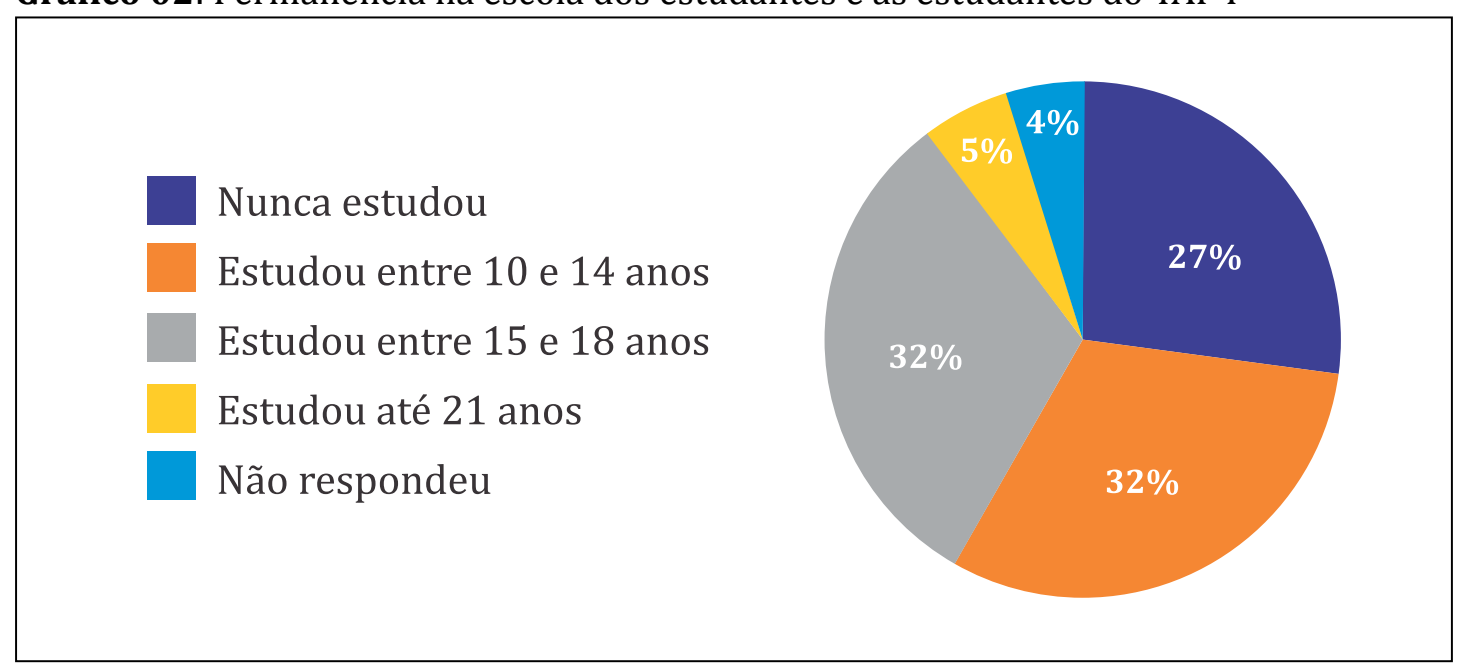

Fonte: Elaborado pelos autores, 2018.

A partir da interpretação desses dados percebemos que os estudantes e as estudantes da EJA, na sua maioria já haviam tentado anteriormente integrar-se ao contexto escolar, pois, $32 \%$ estudou até os 14 anos e $32 \%$ até os 18 anos. Seguido de um percentual considerável de quem nunca estudou, representando por $27 \%$, tendo apenas $5 \%$ de estudantes com idade de estudo até 21 anos e $4 \%$ indefinido por não terem respondido.

Essa reflexão sobre a permanência dos estudantes e das estudantes da EJA, é destacada por Ribeiro (1998) quando reconhece que

Na maioria dos casos, a escolarização é para os adultos uma experiência pregressa que vai se distanciando no tempo e cujos efeitos tenderão a se esmaecer progressivamente se os indivíduos não estiverem em contato com outras agências que promovam o alfabetismo e garantam a funcionalidade das aprendizagens escolares. Identificar essas agências e as formas como exercem essa influência passa a ser uma tarefa essencial quando se tenta explicar habilidades e comportamentos de alfabetismo demonstrados por esse grupo etário (RIBEIRO, 1998, p. 4-5)

As falas de alguns entrevistados e algumas entrevistadas quando questionamos sobre o que foi mais difícil para voltarem à escola revela resistência ao retorno pois acreditam que não conseguem mais aprender por conta da idade ou pelo histórico familiar de muitos não terem estudado, carregando então o estigma de serem incapazes de aprender.

A vergonha de não ter estudado, minha mãe não ter me colocado na escola pequeninha porque ela não tinha como colocar a gente na escola A gente morava nas caatingas, nós tinha uma casa na roça e nossa vida foi sempre trabalhar desde pequenininha (Marília, 55 anos).

Meus pais morreram cedo e eu fui trabalhar em casa de família, aí nunca estudei. A dificuldade porque eu não podia vir, trabalhava na casa de família e elas também não deixavam eu estudar, depois foi que eu arranjei e fui morar com um rapaz foi que ele deixou eu estudar (Sara, 70 anos).

Foi porque eu parei com 10 anos de idade só estudei até a segunda série, e a dificuldade só foi o trabalho porque desde os 10 anos de idade que eu sempre venho trabalhando. Com 16 anos já pagava aluguel, vim de Castro Alves pra cá fiquei um pouco com pai e depois com irmão e fiquei sozinho. Então desde lá trabalhando, pagando aluguel aí me casei e agora estou estudando (Fábio, 58 anos). 
Os dados do gráfico corroboram com as questões trazidas por Oliveira (2007) quando afirma que o adulto da EJA não é o universitário, na sua maioria é retirante, que saem do interior, filhos e filhas de trabalhadores rurais com baixo nível de escolaridade que exercem nas cidades, trabalhos em ocupações desqualificadas, depois de já ter trabalhado na roça na infância ou na adolescência.

No contexto da EJA, os estudantes e as estudantes, por desconhecerem seus direitos à educação, assim como à violação destes direitos, culpabilizam-se por não saber ler e escrever, sendo excluídos de diversas práticas sociais que envolvem a escrita. As situações de preconceitos e discriminação geram vergonha por parte desses sujeitos e muitas vezes os mantém longe da escola por períodos longos desde o último período de estudo, ou por nunca terem estudado, ou ainda pelo medo do desconhecido. Desse modo, o processo excludente de preconceitos traz sofrimento ao analfabeto interferindo diretamente na construção positiva da autoestima, algo não muito explícito na sociedade e gera poucos debates. Como ressalta Vygotsky (1996, p.27).

[...] às populações semianalfabetas eram muitas vezes consideradas, e ainda hoje [...], como algo negativo[...] muitas vezes erroneamente julgada como um tipo de "racismo", eram julgadas não como diferentes, mas como inferiores.

Através das falas percebemos o quanto essas experiências negativas interferem na aprendizagem, retratando os motivos e o tempo pelos quais os adultos se ausentam da escola.

A minha idade, já estava com a idade muito avançada para voltar para o colégio, e também sem poder vir porque do povo (patrões) que sempre tem alguma coisa para mim fa- zer para eu poder não vim como eu fico sem vim muitas vezes por causa das reuniões da Mary Key da filha da minha patroa ai ela me chama para eu ficar com os filhos dela e isso me aborrece muito (Cláudia, 60 anos).

Foi difícil porque eu morava no interior, aí eu tomava conta dos meus irmãos, eu tinha que largar os estudos para tomar conta dos meus irmãos porque minha mãe trabalhava de roça, fazendo o dia, aí eu tinha que tomar conta dos meus irmãos. Aí depois eu casei, arrumei família, minha mãe veio morar em Salvador e eu fiquei na roça e ela veio para aqui (Meire, 30 anos).

0 retorno à escola está diretamente ligado às situações cotidianas nas quais os adultos estão envolvidos (o entendimento da fatura, a leitura do ônibus, o conhecimento dos direitos trabalhistas, conhecer as letras e até mesmo apender a fazer seu nome) e o desejo de conquistar a autonomia para realizá-las, o que potencializa ainda mais a sua aprendizagem. Com base nas respostas dos sujeitos entrevistados, a escola é o lugar de superar a discriminação sofrida pela sociedade por não participarem do mundo letrado, é local de emancipação e desenvolvimento de autonomia para atuar com segurança na realidade.

Essas colocações nos remete a afirmação que a escola da EJA é para uma camada da população desfavorecida e por ter essa condição não são menos capazes. Reiterando, é uma escola que trabalha com o problema da desigualdade, injustiça e exclusão social e é nesse contexto que se torna ambiente de superação, transformação e mudança porque envolve seres inacabados e é essa incompletude que faz da educação uma oportunidade de nos educar constantemente.

Por isso, não podemos nos colocar na posição do ser superior que ensina um grupo de ignorantes, mas sim na posição humilde daquele que comunica um saber relativo a 
outros que possuem um outro saber relativo. (É preciso saber reconhecer quando os educandos sabem mais e fazer com que eles também saibam com humildade). (FREIRE, 2011a. p. 35 e 36)

Trabalhar com a EJA exige do professor uma ação política além da transmissão de conteúdo, exige ação fundamentada em criar possibilidades, despertar curiosidades e reforçar a capacidade de insubmissão. Conforme defende DeAquino (2007), o educador deve ter "uma postura proativa": realizar o diagnóstico para conhecer os aprendizes, ou seja, observar a turma para identificar suas necessidades de aprendizagem atentando-se à diversidade no que tange as experiências anteriores e expectativas atuais; acreditar no potencial e capacidade dos estudantes e das estudantes o que gera incentivo pelo aprender e contextualizar a aprendizagem de forma que o aprendiz perceba a significância do que é produzido em sala de aula a amplie seu conhecimento.

A partir dessas questões, é imprescindível elucidar a identidade cultural dos estudantes e das estudantes como alicerce da prática educativa. A interação entre os sujeitos (estudantes-estudantes e professores-estudantes) sustenta a educação progressiva experienciando a possibilidade de assumirem-se como sujeitos históricos e sociais, aprendentes, transformadores e realizadores de sonhos.

A mediação do professor no processo de aprendizagem dos sujeitos da EJA é de extrema importância e isso nos remete ao papel do professor desafiador que favorece uma educação progressista na prática educativa e nos obriga a refletir constantemente sobre a responsabilidade ética no fazer pedagógico como ação de construir possibilidades e jamais de transmissão de conhecimentos. Essa relação está ligada ao processo dialógi- co do ensinar e do aprender defendido por Paulo Freire ao reconhecer que quem ensina aprende alguma coisa e quem aprende também ensina.

Como defende Paulo Freire (2011b, p 43): “[...] às vezes, mal se imagina o que pode passar a representar na vida de um aluno um simples gesto do professor". É preciso reforçar o caráter indiscutível e socializador da escola a não negligenciar as experiências informais que se vive nela. Devemos enquanto professores e professoras da EJA reforçar a compreensão dos valores sentimentais que expressam emoções e desejos, para emergir a coragem nos estudantes e nas estudantes e superarem a insegurança e o medo porque todo ser inacabado é um ser cheio de vida.

Esse olhar pedagógico e consciente refletido na ação do professor, refletem 15 respostas dentre os 22 dos entrevistados e entrevistadas, como fator positivo que mais influencia a aprendizagem, aparecendo também entre as outras 07 respostas a força de vontade, a leitura e a escrita, as diferentes estratégias de ensino, a concentração e o apoio dos colegas. Em contrapartida, o cansaço (8 respostas entre os 22 entrevistados) se configura como o maior fator negativo, seguidos da vergonha, o barulho em sala, a memória, o trabalho e a falta da leitura e tempo maior para os estudos, sendo esses fatores distribuídos entre as outras 14 respostas.

A ação pedagógica, seja em qualquer modalidade de ensino, necessita de uma ação coletiva de todos da escola de forma a desenvolver a escuta para efetivar uma proposta coerente às demandas os sujeitos, partindo dos saberes do senso comum à construção dos conhecimentos científicos e o desenvolvimento de cidadãos atuantes e, por isso, ativos.

Não é possível respeito aos educandos, à sua dignidade, a seu ser formando-se, à sua 
identidade fazendo-se, se não se levam em consideração as condições em que eles vêm existindo, se não se reconhece a importância dos conhecimentos de experiências feitas com que chegam à escola. 0 respeito devido à dignidade do educando não me permite subestimar, pior ainda, zombar do saber que ele traz consigo para a escola. (FREIRE, 2011b, p. 62)

Com base nas respostas dos entrevistados sobre a questão de como eles aprendem mais, 36\% afirmam que a leitura e a escrita, apesar das dificuldades, são as formas que ajudam mais no seu processo de aprendizagem, 25\% quando a professora ou o professor explica e também se aproxima deles e delas, $22 \%$ quando são trabalhadas aulas de Matemática, $14 \%$ relatam a escrita no caderno e os $3 \%$ quando realizam atividades de grupo.

No cerne da questão, configura-se a importância da Educação de Jovens e Adultos como possibilidade de transformação de pessoas e, em consequência, elas transformarem o mundo, visto que a impossibilidade de desenvolver o exercício pleno da cidadania, os sujeitos não letrados sentemse limitados a participar de situações que envolvem a leitura e a escrita, sentindo-se muitas vezes inferiores pela representação simbólica do uso do polegar na substituição do registro de seu nome.

Essas situações, muitas vezes, afiguramse como sendo estigmas e preconceitos e amplia o desafio da escola em reconhecer o valor cultural desses sujeitos de forma a proporcioná-los situações de práticas de leitura e de escrita para que esses acreditem que são seres capazes e ricos em diversos saberes que por ser diferentes dos exigidos pela sociedade grafocêntrica, não se tornam piores e nem menores que outros saberes. E a partir desses pressupostos, prospectiva-se que a educação escolar se torne de qualidade para atingir os sujeitos e suas especificidades que compartilham de um ambiente de aprendizagem e trocas de saberes, a sala de aula.

\section{CONSIDERAÇÕES FINAIS}

0 processo de aprendizagem dos regressos da EJA é uma análise pertinente visto que os estudantes que desejam ampliar seu repertório no que tange o conhecimento escolar trazem uma bagagem de saberes significativos que necessitam ser reconhecidos, respeitados e valorizados dentro do ambiente escolar para que esses sujeitos se sintam pertencentes e que suas crenças, valores e culturas sejam âncoras para a construção de práticas pedagógicas enriquecedoras que reconhecem a alfabetização para além da decodificação da leitura e da escrita.

Retomando ao problema inicial que incitou essa investigação: quais elementos auxiliam e interferem na aprendizagem dos estudantes e das estudantes do TAP I nas escolas públicas da cidade de Salvador? Percebemos que diversos são os motivos que interferem no processo de aprendizagem dos estudantes e das estudantes da EJA assim como a não permanência na escola devido ao trabalho durante a infância, a vergonha de não saber ler e escrever atrelada à idade que consideram avançada para aprender, ou a inexistência de escolas na localidade na qual residia.

Foi revelador também que o anseio pelo reconhecimento social impulsiona esses sujeitos a buscar instrução, ultrapassar obstáculos, vencer seus medos e suplantar o discurso imposto pela sociedade. Os estudantes e as estudantes da EJA têm como objetivo a satisfação pessoal e a autonomia de poder ir e vir sem depender do outro, assim como, garantir o direito de usufruir dos bens materiais, sociais, culturais e políticos de uma sociedade grafocêntrica. 
Dessa forma, é imprescindível a compreensão do processo de desenvolvimento cognitivo dos estudantes regressos na EJA a fim de construir e implementar as atividades alfabetizadoras capazes de reconhecer suas especificidades e coletividade no contexto cultural de forma a garantir um processo de letramento coeso com a realidade desses sujeitos que favoreça a superação do analfabetismo, auxiliando na construção de seres protagonistas de suas histórias, pertencente às classes menos favorecidas, que necessitam trabalhar para sustentar-se e também estudar por acreditarem na educação como caminho de superação das suas desigualdades sociais, econômicas e culturais.

Nesse contexto de ressignificação da EJA é essencial refletir sobre o fazer pedagógico e a ideologia das escolas voltadas para essa modalidade de ensino reconhecendo os estudantes e as estudantes como trabalhadores e trabalhadoras que possuem uma riqueza de experiências, especificidades sociais, culturais e econômicas e que necessitam do conhecimento científico para superar todas as mazelas que entremearam sua trajetória escolar permeada pela exclusão de direitos. É salutar reconhecer a função reparadora da EJA assim como uma possibilidade real da inclusão dos jovens e adultos nas instituições de ensino, exigindo cada vez mais políticas públicas que efetive essa modalidade de ensino como direito.

É urgente a reflexão nos espaços escolares, com diálogos democráticos, onde todas as vozes vibrantes se façam presentes na construção das propostas pedagógicas, assim como o respeito às especificidades da EJA e a ação educativa para além do mero ensinar conteúdo. Assumir o papel formador de protestar contra as injustiças e exploração, reconhecer a escola como espaço político que contribui para a formação de sujeitos autônomos e históricos capazes de reconhecer-se e reconhecer os outros, cidadãos participativos da sociedade letrada na qual vivemos são as perspectivas nas quais se configura e se constrói a escola cidadã.

\section{REFERÊNCIAS}

ALVES-MAZZOTTI, Alda Judith. Usos e abusos dos estudos de caso. Cadernos de Pesquisa, v. 36, n. 129, p. 637- 651, set./dez. 2006

ANDRÉ, Marli. O que é um estudo de caso qualitativo em educação? Revista da FAEEBA - Educação e Contemporaneidade, Salvador, v.22, n.40, p 95-103, jul./dez 2013.

BRASIL. Instituto Nacional de Estudos e Pesquisas Educacionais Anísio Teixeira. http:// inep.gov.br . Visitado em 26 de out. 2018

BRASIL. Ministério da Educação. Conselho Nacional de Educação. CNE/CEB 11/2000 - HOMOLOGADO. http://portal.mec.gov.br/cne/arquivos/pdf/pceb011_00.pdf. Visitado em 10 de nov. de 2018.

CAMARGO, Maria Rosa Rodrigues Martins; FURLANETTI, Maria Peregrina de Fátima Rotta (Orgs). Educação de pessoas jovens e adultas: múltiplas faces de um projeto educacional: aportes teóricos, práticas de formação, contextos produzidos. São Paulo: Ed. UNESP: PROEX, 2010 .

CONCEIÇÃO. Ana Paula Silva da; OLIVEIRA, Rosemary Lapa de. SANTOS, Josenildes, Zacarias. Constituição do sujeito leitor na educação de jovens e adultos: Um olhar das práticas educativas criativas. Inovação e educação: formação docente e experiências criativas/ organizadoras Graça dos Santos Costa, Nuria Lorenzo Ramírez, Tânia Regina Dantas - Ijuí: ed. Unijui, 2016.

DEAQUINO, Carlos Tasso Eira. Como aprender: andragogia e as habilidades de aprendizagem. 1a edição São Paulo: Pearson Prentice Hall, 2007.

FARIA, E. M. S. A precarização e a (des)profisionalização docente na educação de jovens e adultos trabalhadores. In: VIII Seminário do trabalho, 2018, Marilia-SP. Cadernos de Resumos- VIII Seminário do Trabalho - Trabalho, 
Educação e políticas sociais no século XXI. p. 0113. Marilia-SP, 2012.

FREIRE, Paulo. Educação e Mudança. São Paulo: Paz e Terra, 2011.

Pedagogia da Autonomia: saberes necessários à prática educativa. São Paulo: Paz e Terra, 2011.

GODOY, Arilda Schmidt. Introdução à pesquisa qualitativa e suas possibilidades. Revista de Administração de Empresas. São Paulo, v. 35, n. 2, p. 57- 63, 1995

TRIVIÑOS, Augusto N. S. Introdução à pesquisa em Ciências Sociais: a pesquisa qualitativa em educação. São Paulo: Atlas, 2012.

YIN, Roberto K. Estudo de caso: planejamento e métodos. 5aa ed. São Paulo: Bookman, 2015.

OLIVEIRA, Marta Kohl de. Jovens e adultos como sujeitos de conhecimento e aprendizagem. In.: Educação como exercício de diversidade. Brasília: UNESCO, MEC, ANPEd 2007. 2ª ed (Coleção educação para todos; 7).

ORNELLAS, Maria de Lourdes S. (Entre)vista: a escuta revela. Salvador: EDUFBA, 2011

PALACIO, Jesús. Mudança e desenvolvimento durante a idade adulta e a velhice. In COLL, César; PALACIOS, Jesús; MARCHESI, Álvaro (Orgs). Desenvolvimento Psicológico e Educação - Volume 1: Psicologia Evolutiva. 2a ed. Porto Alegre: Artmed Editora, 2004.

RIBEIRO, Vera Maria Masagão. Alfabetismo e atitudes: pesquisa junto a jovens e adultos paulistanos. Caxambu, MG: ANPEd. Trabalho apresentado na Reunião Anual da ANPEd, 21, Caxambu, 1998.

VÓVIO, Claudia Lemos; KLEIMAN, Angela B. Letramento e alfabetização de pessoas jovens e adultas: um balanço da produção científica. Cad. Cedes, Campinas, v. 33, n. 90, p. 177-196, maio-ago. 2013 Disponível em http://www.repositorio.unicamp.br. Visitado em 04 de dezembro de 2018.

VYGOTSKY, Lev Semionovich; LURIA, Alexander Romanovich. Estudos sobre a história do comportamento: o macaco, o homem primitivo e a criança. Trad. Lólio Lourenço de Oliveira. Porto Alegre: Artes Médicas, 1996.

Recebido em: 19/02/2019

Aprovado em: 06/05/2019 